\title{
MALNUTRITIONAL AMBLYOPIA
}

\author{
By T. KeIth Lyle, M.D., M.ChiR.(Cantab.), M.R.C.P.(Lond.), F.R.C.S.(Eng.)
}

\section{Historical}

One of the first accounts of malnutritional amblyopia was given by Jacob Bontius in 1645 . Chapter XVI in the English translation of his book 'De Medicina Indorum' and quoted by Spillane' is entitled 'Of blindness and weakness of sight to which those are liable who sail to Amboyna and the Moluccan Islands and adjacent firths,' in which it is stated 'the inhabitants of these islands impute it to eating hot rice' and '... the grand specific in this disorder is the liver of the fish Lamia eaten crude with salt ... Bontius speaks of the optic nerves being affected, with no mention of outward abnormality of the eyes. It would therefore appear that he was describing the same condition as is now under discussion and which occurred so commonly in the same part of the world during the recent war, nearly 300 years later.

There have, however, been various references to malnutritional amblyopia prior to the recent war, of which the main are those by Bietti ${ }^{2}$ in I901, Landor and Pallister in Malaya in 1935, and Fitzgerald Moore in West Africa in 1937.

Recently the subject has been thoroughly described by Claffey ${ }^{6}$ of the Australian Army

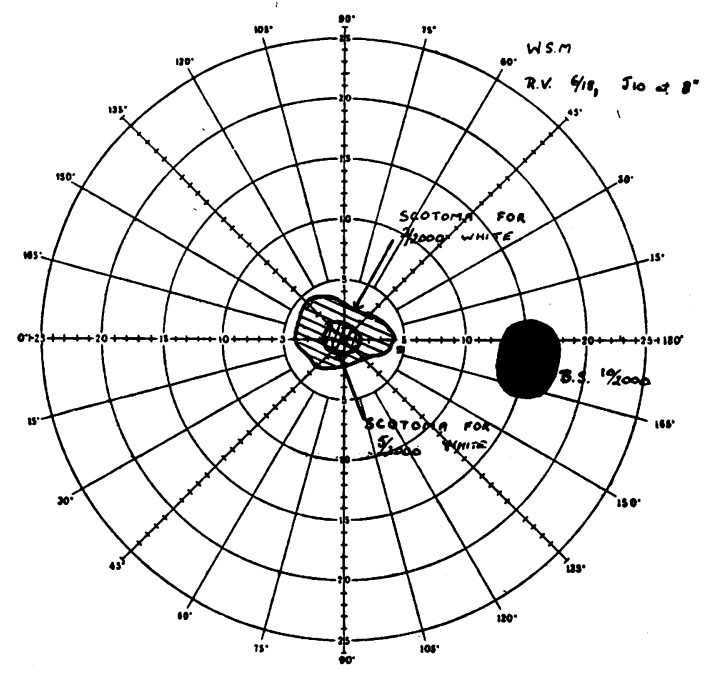

FIG. I
Medical Corps as a result of the investigation of some 2,000 cases seen in. P.o.W. Hospitals in Singapore between 1942 and 1945, also by Ridley $^{7}$ of the R.A.M.C., by Livingston ${ }^{8}$ and by Hobbs and Forbes ${ }^{9}$ of the R.A.F., and by Spillane in his textbook on nutritional disorders of the nervous system.

\section{Nomenclature}

Since it is not certain whether the original lesion causing the visual defect in these cases of nutritional deficiency is one primarily affecting the fibres of the optic nerve or one primarily affecting the ganglion cells or their axis cylinders in the retina, it is preferable to refer to the condition as malnutritional amblyopia rather than as 'retrobulbar optic neuropathy or neuritis' (if we assume that the optic nerve is primarily affected) or as ' retinopathy or retinitis' (if we assume that it is the ganglion cells of the retina or their axis cylinders that are primarily affected).

Before considering the aetiology, pathology and clinical findings in these cases of malnutritional amblyopia, a few typical cases that have recently been followed up and examined will be described. These patients had not the opportunity of being

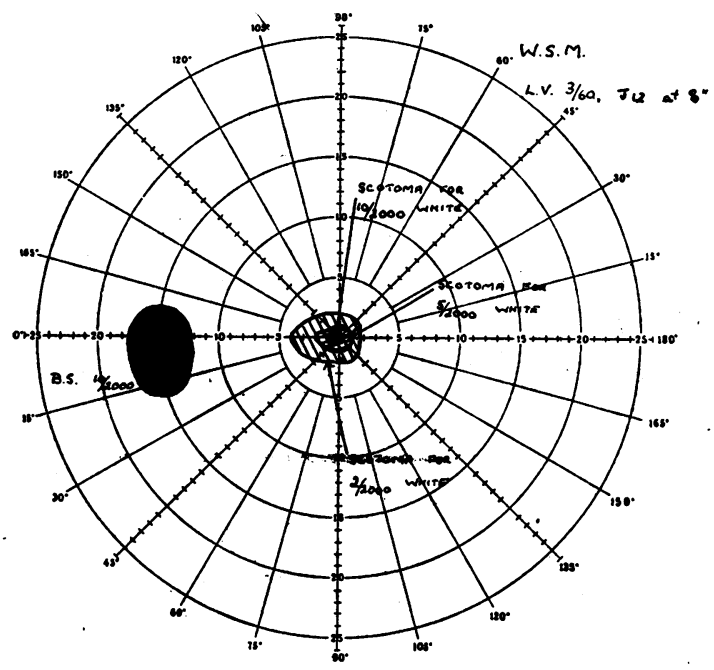

F1G. 2 
thoroughly examined at the time of onset of the symptoms, but only in the later stages, a year or more after the onset of the symptoms.

\section{Case 1}

\section{A.C.I W.S.M., aged 27.}

Prisoner of war in Japanese hands for $3 \frac{1}{2}$ years in Java and latterly in Ambon.

Gradual onset of defective vision after he had been a prisoner for $\mathrm{I} \frac{1}{2}$ years. The trouble started with a pricking feeling in the eyes and then a blurring of vision. Symptoms progressive for four months. Treatment by means of Marmite and liver extract and milk. Slight improvement occurred in the sight. Suffered from wet beriberi just before the eye trouble began.

Present disability. Cannot see to read unless he holds his book very close to his eyes and even then he cannot read for more than a few minutes at a time, and cannot read small print. Cannot see sufficiently well to play games such as football, cricket, darts, etc. (Vision was $6 / 6$ each eye when he joined the Service.)

Present job. Building inspection.

\section{ON Examination}

I. Vision. Right, $6 / 18$ and Jro slowly at 8 in. Left, $3 / 60$ and J12 with difficulty at 8 in. No refractive error.

2. Visual fields. See charts, Figs. I and 2. Central scotomata with proportional colour defect. Charts taken 14 months previously showed approximately the same defect.

3. Ishihara colour vision test. Reads all plates correctly when holding them at 8 in.

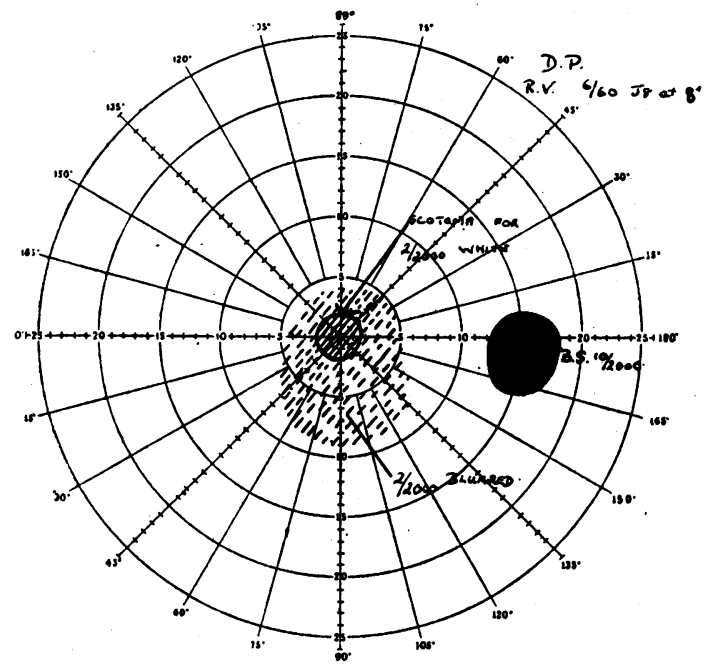

FIG. 3
4. Optic fundi. (a) Optic discs-slight temporal pallor each eye, but only just beyond physiological limits. (b) Macular regions-right, no abnormality; left, a slight degree of pigmentation present and a small atrophic area.

\section{Case 2}

A.C. I D.P., aged 26.

Prisoner of war in Japanese hands for $3 \frac{1}{2}$ years in Java and latterly in Ambon.

Onset of defective vision after he had been a prisoner for two years, fairly gradual in nature, first noticed inability to thread a needle to sew a button on his trousers. Sight became a little worse and then remained stationary. No special treatment.

Present disability. Cannot see to read ordinary print, drive a car or play ball games. (Was a transport driver before P.o.W. and a printer's engineer. in civil life.)

Present job. Works in a warehouse as a cleaner.

\section{On Examination}

I. Vision. Right, $6 / 60$ and $\mathrm{J} 8$ at 8 in. Left, $6 / 60$ and Ji2 at 8 in. No refractive error.

2. Visual fields. Central scotomata (see charts, Figs. 3 and 4 ) with proportional central colour defects.

3. Ishihara colour vision test. Reads all plates correctly when holding them at a distance of 8 in.

4. Pupils. Fairly brisk reaction to light, but react more briskly on convergence.

5. Optic fundi. (a) Optic dics-slight pallor of temporal halves of both dics, but only just

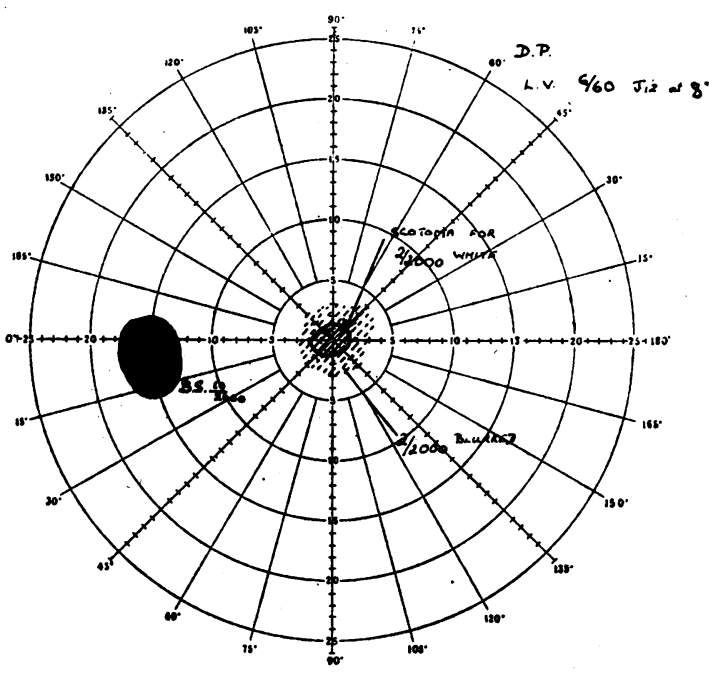

FIG. 4 


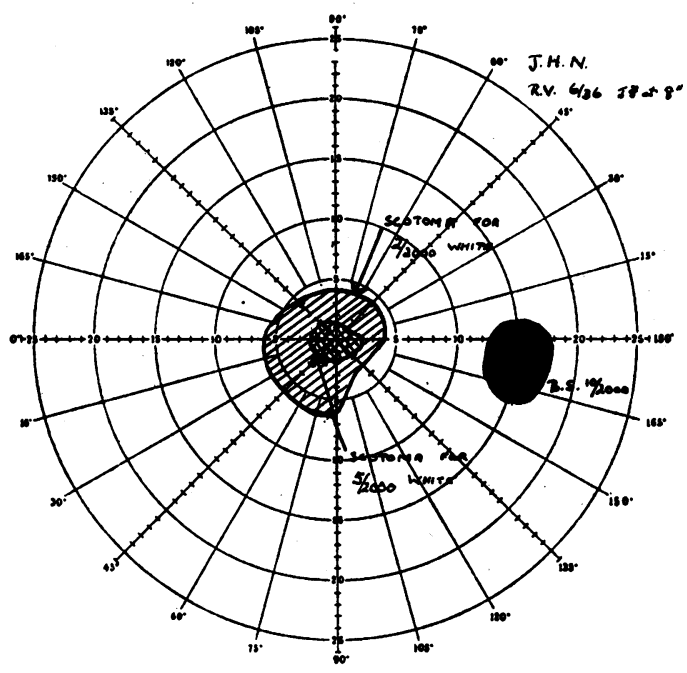

FIG. 5

beyond physiological limits. (b) Macular regions - no abnormality. (c) Blood vessels-no abnormality.

\section{Case 3}

Cpl. J.H.N., aged 28.

Soon after arriving on Ambon after a year's imprisonment on Java his eyes became irritable and vision blurred. First noticed defective vision by failing to observe a Japanese guard. At that time he was doing heavy manual work, building an airfield. No improvement in his sight took place in spite of treatment with yeast water until he returned to Java, where the conditions were better. No improvement for the last two years.

Present disability. Cannot see clearly to read. The print 'dances up and down.'

Present job. Plastic moulder.

\section{On Examination}

I. Vision. Right, $6 / 36$ and J8 at 8 in. with difficulty. Left, $6 / 60$ and Jro at 8 in. with difficulty.

2. Visual fields. Central scotomata in each eye (see charts; Figs. 5 and 6).

3. Ishihara colour test. Reads all plates correctly when holding them at a distance of 8 in.

4. Optic fundi. (a) Optic discs-show some pallor. (b) Macular regions-no abnormality.

\section{Etiology}

Among those affected were men of all ages and of all ranks, although there were fewer officers than

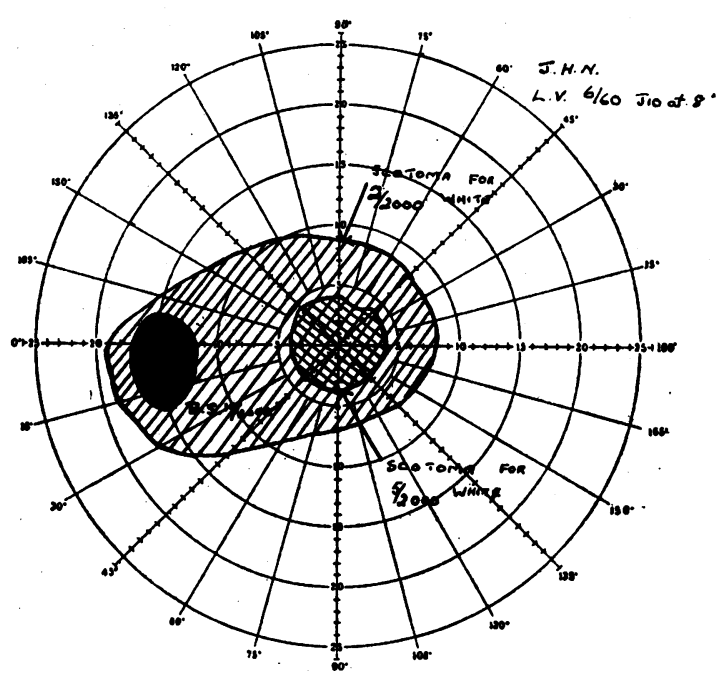

FIG. 6

other ranks. It was said. that the condition was commoner among the Australians than the British on account of the fact that the Australians normally were greater meat eaters.

Predisposing factors were :-

I. Excessive rice consumption with insufficient vitamin B complex to metabolize it. It is certainly not a condition due to starvation. It was not, for instance, reported in the concentration camps of Central Europe, and it did not occur in certain forces that were sent up country in Malaya working in semi-starvation conditions.

2. Exćessive manual work.

3. Intercurrent disease especially dysentery.

It did not appear to be disposed to by tobacco, by the excessive use of the eyes or by such factors as focal sepsis.

It was not especially associated with other manifestations of hypo-vitaminosis, but when such an association occurred the commoner conditions met with were :-

I. Painful feet.

2. Stomatitis, glossitis and scrotal dermatitis.

3. Spastic paraplegia.

4. Beri-beri.

5. Nerve deafness.

\section{Symptoms}

Those of a bilateral central visual field defect, usually of gradual onset, but sometimes of fairly sudden onset, consisting of difficulty in the 


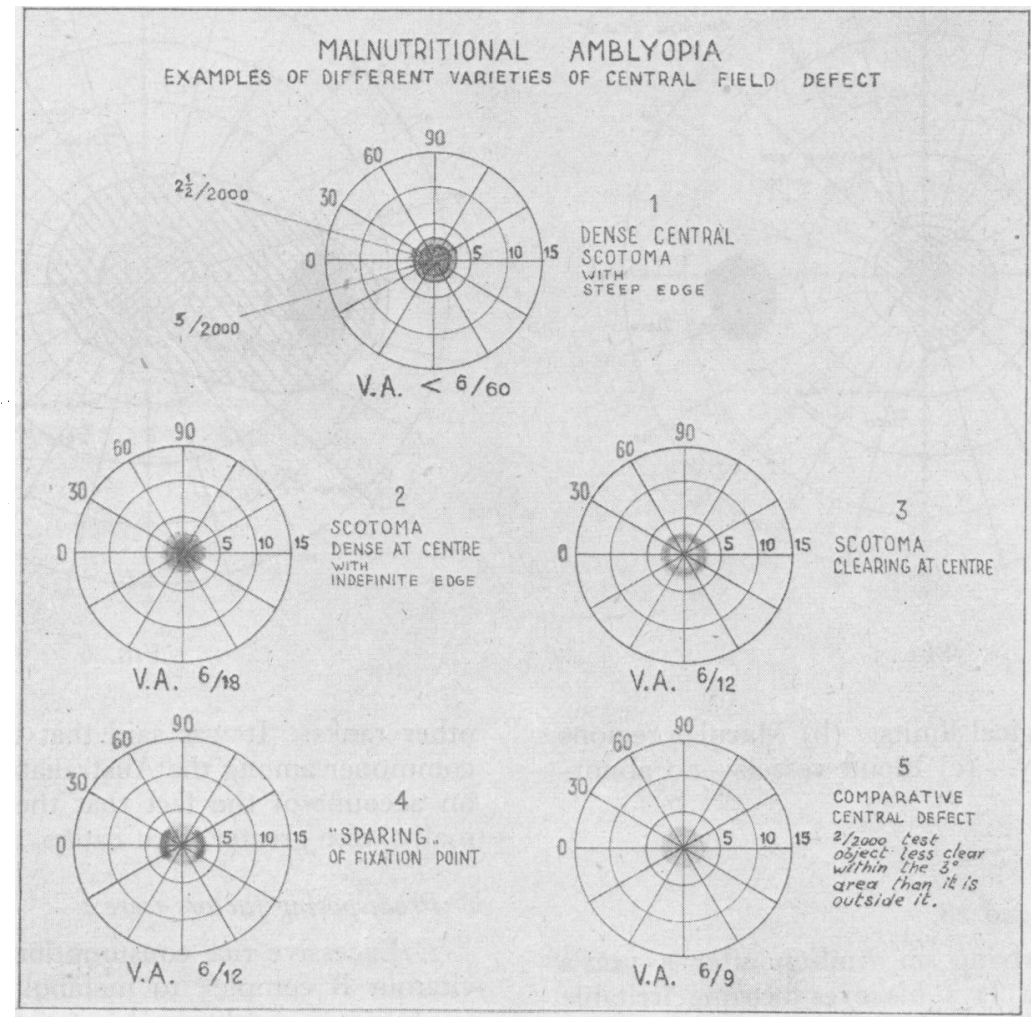

Fig. 7

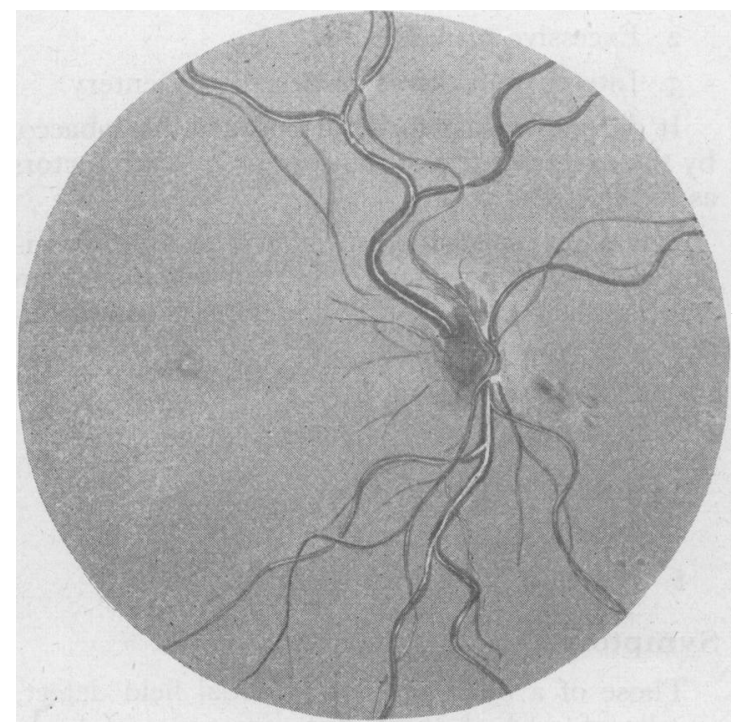

Fig. 9

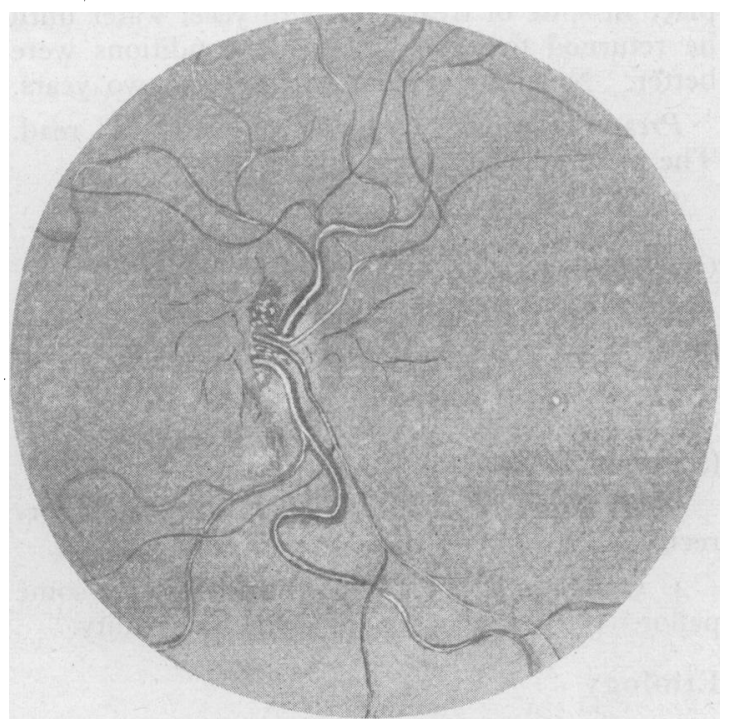

Fig. 10 
recognition of people's features or difficulty in reading, sometimes associated with pain or aching behind the eyes and photophobia.

\section{Signs}

I. Visual acuity. Varied from $2 / 60$ to $6 / 9$. The eyes were often unequally affected, but they were always both affected.

2. Visual fields. (a) Peripheral-usually normal. Spmetimes a slight general depression. (b) Central-a central, paracentral or centro-caecal scotoma. No obvious disproportion between the white and colour fields as in tobacco amblyopia. Fig. 7 shows some of the varieties of central field defect met with in the later and stationary stage of the condition.

3. Pupil reactions. Usually somewhat sluggish to light, but not markedly so.

4. Fundi, Acute stages. No abnormality, or slight ' disc oedema.' Sometimes macular oedema with enlarged calibre of the veins and occasionally a few retinal haemorrhages. Claffey reported that fundus abnormalities were present only in about I per cent. of the cases, whereas Schwartz ${ }^{10}$ found them much more commonly., Later stages. No obvious abnormality or pallor of the temporal half of the optic disc, its degree varying with the severity of the case. In some cases there are dots of pigmentation and small atrophic areas in the macular region. The presence of these was emphasized by Livingston.

\section{Clinical Course of the Condition}

Cases that were untreated tended to get worse or to remain stationary.

In cases that were given treatment, the condition was either arrested or it improved, commencing to do so in the second week of treatment and reaching a maximum in six months.

The earlier treatment was commenced the better the prognosis.

It is doubtful if treatment was of the slightest value if not commenced before two months from the onset of the condition.

\section{Treatment given}

Every type of vitamin was given in one way or another in different centres, but the consensus of opinion was that the most important was the ' $B$ ' complex, which was usually available in the form of Marmite.

\section{Discussion as to the Pathology}

From the description of the appearances of the fundi in certain of the cases observed, it would appear that the lesion is either at the optic nerve head, or in the macular region, or both. In most of the cases described however no such changes have been observed.

There have been few opportunities for histological examination of the optic nerves and retina in any of the recent cases, except in one instance in which Greenfield found no abnormality. This was one of Spillane's cases in which there was a known history of malnutritional amblyopia. It was, however, a slight case only, the visual acuity not deteriorating below $6 / 18$ and subsequently improving to $6 / 9$ before the patient, a German P.o.W. in the Middle East, committed suicide.

Bietti in r9or examined post mortem some cases of pellagra in which optic neuritis had been a symptom and found no evidence of histological abnormality in the optic nerves and retinae. On the other hand, Scott $^{3}$ in 1918 in Jamaica, reporting on nutritional diseases affecting labourers in a cane sugar plantation found degeneration in the optic nerves at autopsy.

The fact that there may be no demonstrable pathological lesion does not prove the absence of a lesion. Bearing in mind the limited capacity of recovery of damaged nerve tissue, a lesion previously present may clear up macroscopically or even microscopically, but leave behind a functional defect. There appears little doubt that the condition is caused by some factor present in carbohydrates or produced in carbohydrate metabolism, which factor is normally neutralized by adequate intake of the vitamin $\mathrm{B}_{2}$ complex. Precisely what the factor is or how it acts is not known.

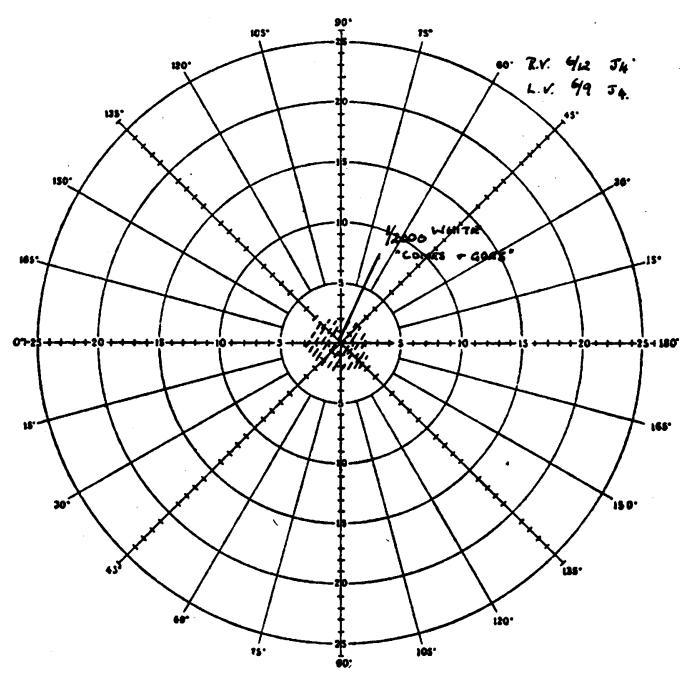

Fig. 8 
Stannus has suggested the theory of 'capillary dysergia,' causing a localized oedema and/or ischemia, in order to explain the fluctuating character of many of the early symptoms of these deficiency states.

With regard to the probable 'vascular' pathology of the lesion, the following case which was seen recently may serve to illustrate certain points, as it would appear to be of similar etiology :-

Mrs. C. S., aged thirty-two, had gradually noticed that her vision was blurred for the last two or three weeks and that she could not see clearly to read or paint. (She is an artist who mainly does water colour pictures.) Her visual acuity could not be improved beyond right, 6/12 and $\mathrm{J}_{4}$, left, $6 / 9$ and $\mathrm{J}_{4}$. No definite central or para-central scotoma was demonstrable, but there was an area around the fixation point in which the smallest test object (I/2,000 white) appeared to ' come and go' (Fig. 8). The appearance of the optic fundi was. interesting. There was an obvious dilation of the retinal veins which also appeared tortuous, and there were a few small haemorrhages at the edge of both optic discs (see fundus pictures, Figs. 9 and ro, which have been kindly drawn and painted for me by my colleague, Hugh Ryan, F.R.C.S.).

Her case was thoroughly investigated as an inpatient, and every conceivable examination, both relevant and irrelevant, was carried out. No abnormality was discovered clinically. Her blood pressure was normal, W.R. negative, C.S.F. normal, blood count and blood sedimentation rate normal. An electro-cardiogram was normal, as also was the result of a barium meal, barium enema and sigmoidoscopy.

She was, however, somewhat under-nourished, and had for many months been taking very little in the way of solid food, her main article of diet being whisky. This was largely due to the fact that she was under the impression she had a weak stomach. There were, as one might expect, certain psychological factors underlying the condition.

After two weeks spent in a nursing home on a balanced diet, there was a definite improvement. Her vision with correction had improved to $6 / 9$ and $6 / 6$ in the right and left eye respectively, and the haemorrhages in the retinae had completely disappeared, although the retinal veins remained abnormally distended but to a less degree.

This case appears to be of the same type as those under consideration, seen at an early stage. It will be interesting to re-examine the patient later in order to follow the clinical course of the condition.

\section{Differential Diagnosis}

As the condition of malnutritional amblyopia has some resemblance to acute retro-bulbar optic neuritis and to tobacco amblyopia, it would be as well to compare certain aspects (see table).

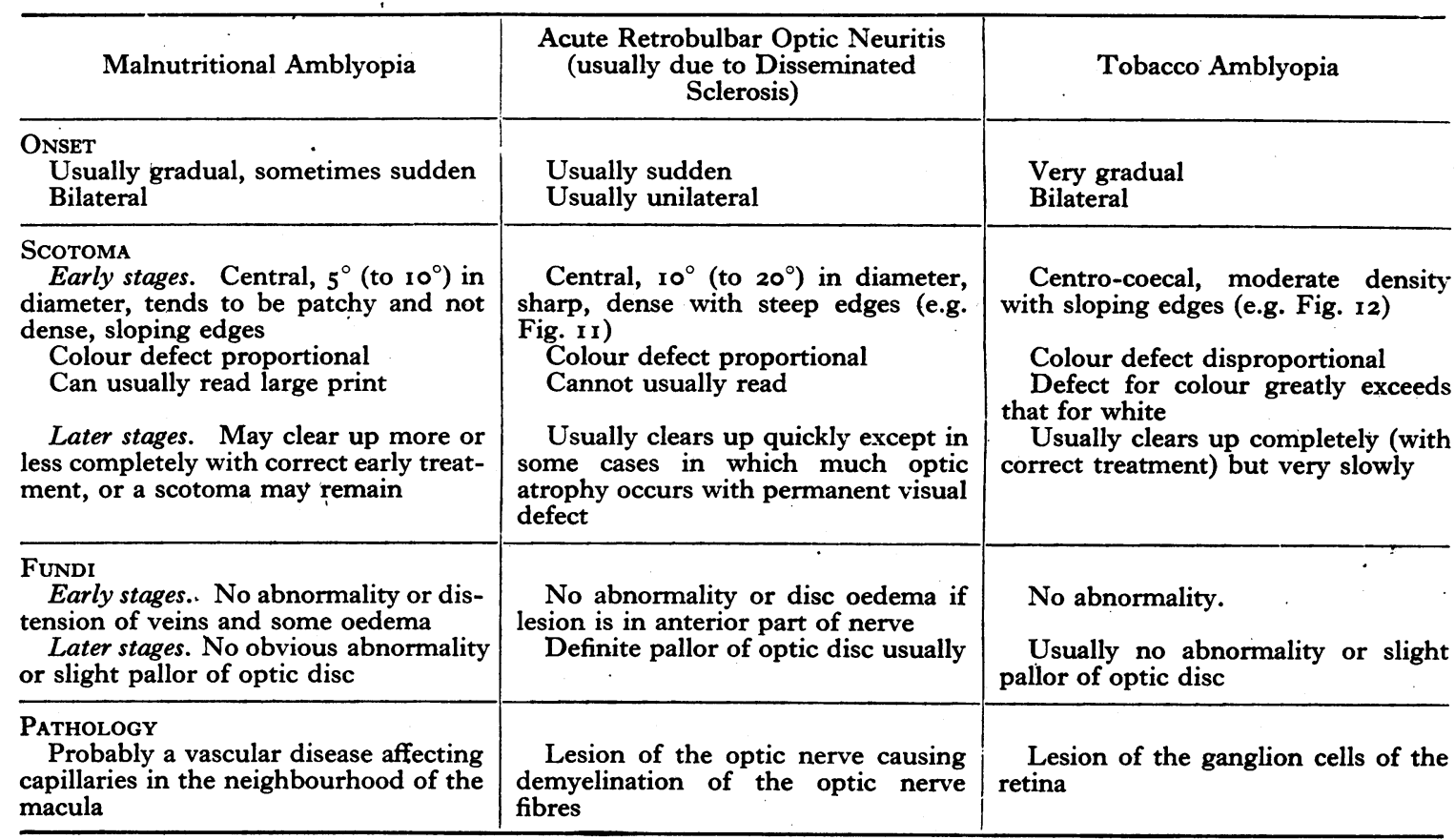




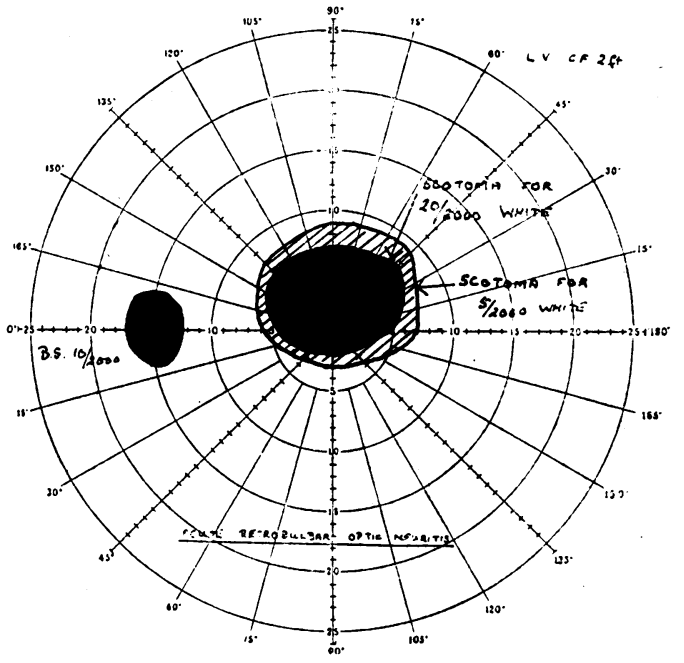

FIG. II

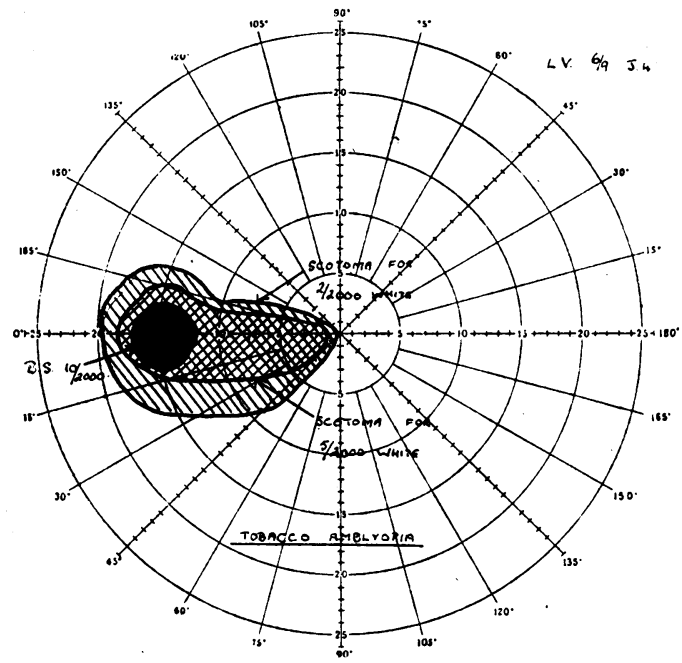

FIG. 12

\section{REFERENCES}

I. SPILLANE, J. D. (I947), ' Nutritional Disorders of the Nervous System,' E. \& S. Livingstone, Edinburgh.

2. BIETTI, A. (1901), Klin. Mon. f. Aug., 39, 337, 450, quoted by Marie, 1910, and by Spillane, 1947.

3. SCOTT, H. H. (I918), Ann. Trop. Med. Parasilot., 12, 109, quoted by Spillane, 1947.

4. STANNUS, H. S. (1945), Brit. Med. F., quoted by Spillane.

5. SPILLANE, J. D., and SCOTT, G. I. (1945), Lancet, 2, 25 I.
6. CLAFFEY, F. P. (1945), ' Report on Ocular Deficiency Diseases in Singapore Prisoner-of-War Hospitals, 1942-45.'

7. RIDLEY, H. (1946), 'Transactions of the Ophthalmological Society of the U.K.'

8. LIVINGSTON, P. C. (1946), Ibid.

9. HOBBS, H. E., and FORBES, F. A. (1946), Lancet, Aug. 3, 1946, p. 149 .

10. SCHWARTZ (1946), Private communication 'Neuropathia of the Optic Nerve by Central Neuritis.'

'These English are a ferocious race; what crimes there are in their history. Think of Henry VIII marrying Lady Seymour the day after he had had Anne Boleyn beheaded. We should never have done such a thing in our country. Nero never committed such crimes. And Queen Mary? Ah? The Salic Law is an excellent arrangement?'

Napoleon at St. Helena. 